\title{
Observaciones sobre el lenguaje de Romeo y Julieta
}

\author{
María Enriqueta GONZÁLEZ PADILLA \\ Universidad Nacional Autónoma de México
}

Romeo y Julieta 1 marca un nuevo comienzo en el estilo de Shakespeare. El dramaturgo llegó a esta obra después de la larga y agotadora práctica de los dramas históricos y de las comedias de la primera época. Desde el punto de vista del lenguaje, en Romeo y Julieta se nota menos presión (como si el autor se hubiese liberado de una carga pesada) y un mayor sentido crítico por lo que hace al empleo del lenguaje de las primeras comedias. Estamos pues ante el inicio de un periodo de experimentación, y el único pasaje en que se deja sentir el estilo pesado de la vieja arenga civil es el discurso del Príncipe en la primera escena:

Rebellious subjects, enemies to peace,

Profaners of this neighbour-stained steel, Will they not hear? What, ho! You men, you beasts, That quench the fire of your pernicious rage With purple fountains issuing from your veins, On pain of torture, from those bloody hands Throw your mistemper'd weapons to the ground, And hear the sentence of your moved prince.

Súbditos rebeldes, enemigos de la paz, que el acero profanáis con sangre de vecinos, ¿No querrán escuchar? ¡Cómo, pues! ¡Hombres, bestias, que apagáis el fuego de vuestra inquina perniciosa con purpúreas fuentes que brotan de vuestras venas, so pena de tortura,

' La obra ha sido vertida al español dentro del Proyecto Shakespeare que dirige la autora de este artículo. De ahí que las citas estén traducidas. 
arrojad al suelo de vuestras manos sangrientas

esas armas destempladas,

y escuchad la sentencia de vuestro airado príncipe!

La formalidad deliberada del estilo separa este pasaje del resto de la obra.

En contrase con Trabajos de amor perdidos, donde el interés en el lenguaje era la única preocupación, Shakespeare trata en Romeo y Julieta de usar un estilo más dramático, al servicio de la acción y de la idiosincrasia de los personajes, pero con la viveza y hermosura que convienen a una tragedia romántica. Para ello, se valió del soneto y de todo lo que, en cuanto atmósfera y estilo, implicaba éste en el Renacimiento, sobre todo a partir de que el género alcanzara gran boga con el Astrophel and Stella de Sir Philip Sydney. En consecuencia, hay varios pasajes de Romeo y Julieta que están redactados en forma de sonetos. Tales son, desde luego, los coros a los actos I y II, el primero de los cuales resume de modo admirable toda la tragedia y que reza así:

CHORUS: Two households both alike in dignity (In fair Verona, where we lay our scene) From ancient grudge break to new mutiny, Where civil blood makes civil hands unclean. From forth the fatal loins of these two foes A pair of star-cross'd lovers take their life, Whose misadventur'd piteous overthrows Doth with their death bury their parents' strife. The fearful passage of their death-mark'd love And the continuance of their parents' rage, Which, but their children's end, nought could remove Is now the two hours' traffic of our stage; The which, if you with patient ears attend, What here shall miss, our toil shall strive to mend. (Prologue)

Coro: Dos familias en posición muy semejantes (en la hermosa Verona do situamos nuestra escena) por antiguos rencores en disturbios estallan, tiñendo de sangre incivil las manos ciudadanas.

De la fatal entraña de estos dos enemigos bajo estrellas contrarias, cobra vida una pareja de amantes, los que junto con sus lamentables desventuras con su muerte enterrarán la pugna de sus padres. 
El tránsito terrible de su trágico amor y la perseverancia del odio de sus padres, que nada pudo aplacar hasta morir los hijos, brindará estas dos horas materia a nuestro drama, el cual si escucháis con oídos pacientes, las faltas que en él haya habremos de enmendar.

Y está luego en forma de soneto también la descripción que la madre de Julieta hace del Conde Paris, en que maneja con acierto y elegancia la comparación barroca del pretendiente de su hija con un libro precioso:

Read o'er the volume of young Paris' face

And find delight writ there with beauty's pen;

Examine every married lineament

And see how one another lends content,

And what obscured in this fair volume lies

Find written in the margent of his eyes.

This precious book of love, this unbound lover,

To beautify him, only lacks a cover:

The fish lives in the sea, and 'tis much pride

For fair without the fair within to hide:

That book in many's eyes doth share the glory, That in gold clasps locks in the golden story;

So shall you share all that he doth possess, By having him, making yourself no less.

(I.3.81)

Lee el volumen del rostro de este joven

y descubre el deleite inscrito ahí

con una bella pluma.

Examina esas facciones que tan bien armonizan

y ve cómo una y otra se combinan,

y lo que obscuro quede en este hermoso volumen,

lo encontrarás escrito en el margen de sus ojos.

Este pequeño libro de amor,

este amante a la rústica,

para ser más hermoso

solamente de cubierta precisa.

En el mar vive el pez y es un orgullo

que la belleza externa recubra

la que ha quedado oculta.

A los ojos de muchos participa ese libro

de la gloria, que con broches de oro, encierra 
una dorada historia.

Al tenerlo tú participarás también

de cuanto él posee,

sin disminuir tú misma para nada.

Es de notar que el efecto de este pasaje decorativo se realza por contraste con el realismo que, en verso también, logra Shakespeare imprimir al parlamento de la nodriza en esta misma escena:

Even or odd, of all days in the year,

Come Lammas-eve at night shall she be fourteen.

Susan and she - God rest all Christian souls!-

Were of an age: well, Susan is with God.

(1.3.16)

Pues dias o no, de todos los del año,

la vigilia de la fiesta por la noche

cumplirá los catorce.

Susana y ella (Dios les dé el descanso

a las ánimas de todos los cristianos)

eran de la misma edad.

Bueno, Susana está con Dios.

Por otra parte la relación de Romeo con Rosalina se describe con los términos convencionales, muchos ya decadentes, del soneto pospetrarquista; pero éstos de propósito están exagerados para sugerir lo artificioso de una relación amorosa en que Romeo actúa por mera pose, aun sin darse cuenta:

$\mathrm{O}$ anything of nothing first create!

$O$ heavy lightness, serious vanity,

Misshapen chaos of well-seeming forms,

Feather of lead, bright smoke, cold fire, sick health,

Still-waking sleep, that is not what it is!

This love feel $\mathrm{I}$, that feel no love in this.

(I.1.174)

u odio enamorado!

[...] ¡Oh amor pendenciero.

¡Oh suma de todo, de la nada creado!

¡Oh ligereza pesada y vanidad austera,

informe caos forjado de bellas apariencias!

¡Pluma de plomo y humo todo resplandeciente, 
fuego frígido y enferma robustez,

sueño que siempre velas que no es lo que es!

Este amor siento yo que amor no siento en esto.

El tratamiento del soneto puede llegar hasta la parodia, como sucede en II.4.40, en que Mercucio se ríe en prosa de los excesos de Romeo:

Now is he for the numbers that Petrarch flowed in:

Laura to his lady was but a kitchen wench; marry, she had a better love to be-rhyme her; Dido a dowdy; Cleopatra a gypsy; Helen and Hero hildings and harlots; Thisbe a grey eye or so, but not to the purpose.

Ahora está por la lira de Petrarca. Laura, junto a su señora, era una criada de cocina (conste que tenía mejor amante que le cantara sus rimas). Dido, una Maritornes, Cleopatra, una gitana, Elena y Hero, unas prostitutas buenas para nada, Tisbe, una que tenía los ojos garzos, o algo asi, cuya historia no viene al caso.

La evolución de Romeo bajo el influjo del amor de Julieta acarrea una transformación muy convincente en su manera de hablar. Al ver a la joven por primera vez brota de sus labios, como empujada a presión, una serie de bellísimas imágenes que denotan una auténtica emoción:

$\mathrm{O}$, she doth teach the torches to burn bright!

It seems she hangs upon the cheek of night

Like a rich jewel in an Ethiope's ear;

Beauty too rich for use, for earth too dear!

(I.5.46)

¡Oh, ella enseña a brillar espléndidamente

a las antorchas!

Diríase que cuelga

sobre la mejilla de la noche

como una rica joya del oído

de un etíope.

¡Belleza demasiado rica para gastarla, demasiado preciosa para este mundo!

Con este desahogo dramático se pone al descubierto el fuerte sacudimiento sentimental del personaje. Su exaltación romántica contrasta la luz con las tinieblas, y el brillo de la alhaja con la negrura exótica de la tez del etíope. 
El soneto en que Romeo se le declara a Julieta es el más memorable de la obra, con el dúo que gira en torno a la comparación del voto del amante con el del peregrino, y con ese acento grave, solemne y misterioso como el de un rito, que casi fuerza al oyente a retener la respiración.

ROMEO: If I profane with my unworthiest hand This holy shrine, the gentle fine is this:

My lips, two blushing pilgrims, ready stand

To smooth that rough touch with a tender kiss.

JULIET: Good pilgrim, you do wrong your hand too much

Which mannerly devotion shows in this;

For saints have hands that pilgrims' hands do touch,

And palm to palm is holy palmer's kiss.

ROMEO: Have not saints lips, and holy palmers too?

JULIET: Ay, pilgrim, lips that they must use in prayer.

ROMEO: O then, dear saint, let lips do what hands do;

They pray, grant thou, lest faith turn to despair.

JULIET: Saint do not move, though grant for prayers' sake.

ROMEO: Then move not, while my prayer's effect I take.

Thus from my lips, by yours, my sin is purged.

(I.5.95)

ROMEO: Si con mano indigna me atrevo a profanar este santuario, dulce pecado es éste:

mis labios, ruborosos peregrinos, prestos están

a suavizar tan rudo contacto con un beso.

JULIETA: Buen peregrino, harta injusticia hacéis a vuestra mano que tan cortés devoción en ello muestra, pues manos tienen los santos que el peregrino toca y palma con palma es de palmeros beso.

ROMEO: ¿No tienen labios los santos igual que los palmeros?

JULIETA: Sí, peregrino, labios que en orar se emplean.

ROMEO: Oh entonces dejad, querida santa, que mis labios hagan lo que las manos hacen:

rezan ambos. Oíd vos la petición, no sea que la fe en desesperanza se convierta.

JULIETA: Los santos no se mueven aunque escuchen plegarias.

RoMEo: No os mováis pues mientras recojo

el fruto de mis preces.

Asi de mis labios por vos el pecado se absuelva.

Las imágenes de luz y tinieblas de que hablábamos antes serán recurrentes. Romeo las usa copiosamente en la famosa escena del balcón (II.1.26), 
donde revelan de modo muy eficaz su deslumbramiento interior al ver a Julieta, pero es en el acto $v$ donde el estilo del enamorado adquiere la mayor naturalidad y contundencia trágica:

\section{O my love! my wife!}

Death, that hath suck'd the honey of thy breath, Hath had no power yet upon thy beauty:

Thou art not conquer'd; beauty's ensign yet Is crimson in thy lips and in thy cheeks, And death's pale flag is not advanced there. (v.3.91)

¡Oh amor, esposa mía, la muerte

que ha chupado las mieles de tu aliento no ha tenido aún poder sobre tu belleza! ¡No has quedado vencida!

La enseña de la hermosura es todavía carmín en tus labios $y$ en tus mejillas, y el pálido estandarte de la muerte no ha llegado ahí.

El verso de Julieta también cobra fuerza a medida que avanza la obra, si se observa por ejemplo lo ingenuo de sus lamentos a propósito del apellido de Romeo en la escena del balcón:

O Romeo, Romeo, wherefore art thou Romeo?

Deny thy father and refuse thy name.

Or if thou wilt not, be but sworn my love

And I'll no longer be a Capulet.

(II.2.33)

Oh Romeo, Romeo ¿por qué eres tú Romeo?

Reniega de tu padre y abjura de tu nombre.

$O$ si te resistes a hacerlo, tan solo jura

que me amas,

y no seré yo ya una Capuleto.

O lo pragmático de sus indicaciones al despedirse ahí mismo de su amado:

Three word, dear Romeo, and good night indeed.

If that thy bent of love be honourable,

Thy purpose marriage, send me word tomorrow 
By one that I'll procure to come to thee,

Where and what time thou wilt perform the rite,

And all my fortunes at thy foot l'll lay,

And follow thee my lord throughout the world.

(lbid., 142)

Tres palabras, mi querido Romeo,

y buenas noches de verdad. Si la inclinación

de tu amor es honrada,

tu propósito el matrimonio,

mándame decir mañana

con alguien que voy a enviarte, dónde y a qué hora

se realizará la ceremonia, y a tus pies

pondré cuanto poseo, $y$ te seguiré

mi dueño y mi señor por todo el mundo.

Y se les compara con los versos de mayor aliento, de tono más audaz y más maduro con que, recién desposada, invoca Julieta a la noche que debe ser el ámbito propio de su amor.

Gallop apace, you fiery-footed steeds, Towards Phoebus' lodging. Such a waggoner

As Phaeton would whip you to the west

And bring in cloudy night immediately.

Spread thy close curtain, love-performing night,

That runaway's eyes may wink, and Romeo

Leap to these arms untalk'd-of and unseen.

(III.2.1)

Corred veloces, vosotros corceles

de flamígeros pies,

hacia la morada de Febo. Un auriga

semejante a Faetón

os fustigaria hacia el ocaso, y traería

de inmediato la noche oscura.

Extiende tu espeso velo, noche

que consumas el amor,

para que los ojos del fugitivo

se entrecierren

y Romeo se lance a mis brazos sin ser visto ni oído.

O con el rebuscamiento y sutileza de las respuestas que le da a su padre cuando, ya casada, él quiere obligarla a que acepte a Paris: 
CAPULET: Doth she not give us thanks?

Is she not proud? doth she not count her blest

Unworthy as she is that we have wrought

So worthy a gentleman to be her bride?

JULIET: Not proud you have, but thankful that you have.

Proud can I never be of what I hate

But thankful even for hate that is meant love.

(III.5.142)

CAPUlETO: ¿Qué no nos da las gracias? ¿No se siente orgullosa?

¿No piensa que es una bendición,

que indigna como es,

le hayamos conseguido como novio

un partido tan noble?

JULIETA: No, no orgullosa de que lo hayáis hecho,

pero sí agradecida, Orgullosa

no puedo estar nunca de lo que aborrezco,

pero si agradecida incluso por el odio

que tiene intenciones de amor.

Mientras así se vigoriza y se refina el verso de los dos enamorados, los parlamentos de Mercucio adquieren esa perspicacia analítica e ingeniosa que tendrán después los de Hamlet. La mayor parte de las veces se trata sólo de bromear, como en el ejemplo que propone el profesor Evans ${ }^{2}$ en que Mercucio juega con la palabra "consort", que deriva de otra similar que le ha dirigido Teobaldo (III.1.48). Pero la cosa se vuelve muy peligrosa cuando Mercucio es tan terco y el adversario a quien está provocando es el "Rey de los Gatos" que le tira una estocada mortal. Entonces los juegos de palabras del herido adquieren un acento casi escatológico y auguran el final trágico de toda la obra.

ROMEO: Courage man, the hurt cannot be much.

MERCUCIO: No, 'tis not so deep as a well, nor so wide as a church door, but 'tis enough ' $t$ will serve. Ask for me tomorrow and you shall find me a grave man.

(Ibid., 96)

ROMEO: Valor, hombre, la herida no puede ser gran cosa.

Mercucio: No, no es tan honda como un pozo, ni tan ancha como

${ }^{2}$ Ifor Evans (The Language of Shakespeare's Plays, p. 84) habla de cómo, cuando Teobaldo dice "thou consort'st with Romeo", Mercucio se coge de la palabra "consort" $y$ hace juegos de palabras con ella. 
una puerta de iglesia, pero será suficiente; con eso bastará. Preguntad por mi mañana y me hallaréis en la fosa.

$\mathrm{Y}$ aquí es donde se aprecia el valor de las ediciones anotadas: "a grave man' con el doble sentido intraducible de 'grave', grave y 'grave', tumba. Mercucio se burla de su propia muerte que habrá de convertirlo, mal que le pese, en hombre serio". Esto es lo que reza mi nota a este pasaje en la traducción de Romeo y Julieta que apareció en 1997 dentro de la colección Nuestros clásicos de la UNAM.

Bibliografía

ASTRAna MARín, Luis, Romeo y Julieta, en Obras completas de Shakespeare. Madrid, Aguilar, 1951.

BROOKE, Nicholas, Shakespeare's Early Tragedies. Londres, Methuen, 1973.

Evans, Ifor, The Language of Shakespeare's Play. Londres, Methuen, 1964.

GibBons, Brian, ed., The Arden Shakespeare Romeo and Juliet. Londres, Routledge, 1980.

MAHOOD, M. M., "Wordplay in Romeo and Juliet", en Laurence LERNER, ed., Shakespeare's Tragedies. Middlesex, Penguin Shakespeare Library, 1970. 